\title{
Enhancement of Power Generation in Thermal Power Plant Using MHD System
}

\author{
R. Poonthamil ${ }^{1}$, S. Prakash ${ }^{2}$ \& Dr. S. Anand Kumar Varma ${ }^{3}$ \\ ${ }^{1,2 \& 3}$ Department of Civil Engineering \\ V.S.B Engineering College, Karur - 639111. Tamil Nadu-India
}

\begin{abstract}
In India 80 percent of power generation is from coal fired thermal power plants. To fulfil the deficiency of electrical energy further enhancement of power plants is taking place, thereby causing severe air pollution. Present investigation deals with the enhancement of power generation in the existing power plants by incorporating the MHD system and also which reduces the air pollution problem. In MHD generator, electrically conducting fluid plasma (flue gases of power plant at very high temperature) is passed through a strong magnetic field there by generating electricity. It is predicted that by incorporating MHD system in Tuticorin thermal power plant, $10 \%$ of extra power can be generated along with the usual generation. By attaching this MHD system in all thermal power plants in India, we can add $10 \%$ extra production of electrical energy to the current generation.
\end{abstract}

Key words: Electrical Energy; MHD Generator; Plasma; Magnetic Field; Thermal Power Plant

\section{Introduction}

Magneto hydrodynamic (MHD) power generation utilizes the high temperature plasma incising magnetic force line to induce electromotive force. The conversion process [2] in MHD was initially described by Michael Faraday in 1893. However the actual utilisation of this concept remained unthinkable. The first known attempt to develop an MHD generator [3] was made at Westing house research laboratory (USA) around 1936.

The efficiencies of all modern thermal power generating system lies between $35-40 \%$ as they have to reject large quantities of heat to the environment. In all other conventional power plant, first the thermal energy of the gas is directly converted into electrical energy. Hence it is known as direct energy conversion system. The MHD power plants are classified into open and closed cycle based on the nature of processing of the working fluid with the present research and development programmes, the MHD power generation [7] may play an important role in the power industry in future to help the present crisis of power.

\section{Principle of MHD}

Magneto hydrodynamic (MHD) power generation has been studied as a novel commercial power plant due to its inherent advantage of high-efficiency with high-working temperatures. In an MHD generator, electricity conductive fluid is moving across magnetic field as an armature coil is rotating in magnetic field in the rotating generator. It is obvious that power generation is an energy conversation process. If electric power is extracted in an MHD generator, Lorentz force of output current and applied magnetic field acts to decelerate the working plasma, and therefore, the working plasma losses its enthalpy which is converted into electric power in the MHD generator [3] shown in figure 1.

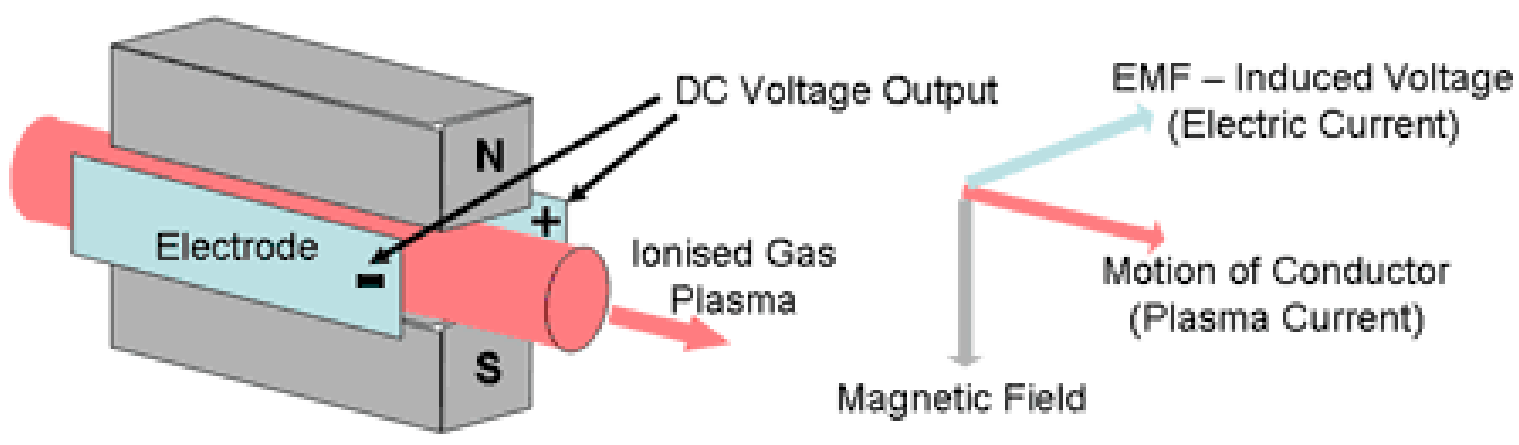

Figure 1 Magneto hydrodynamic (MHD) power generation (principle) 


\section{Operation of MHD}

Magneto hydrodynamics (MHD) is a promising technology for electric bulk power generation. MHD is accomplished by forcing electrically conducting fluid or a plasma through a channel with a magnetic field applied across it and electrodes placed at right angle to flow and field (Figure 1). An MHD plant can be directly fired with coal and there are no moving parts. To achieve extra high efficiencies, MHD combined in a binary thermodynamic cycle with a conventional steam plant to add an extra 40 percent to the total power output and to boost the overall combined efficiency into the 60 percent range [1] shown in figure 2 . The high temperature MHD process extracts parts of the heat energy in the plasma at the high temperature end. The gas leaving the MHD generator, at relatively high temperatures, is then used in a conventional bottoming steam plant [4].

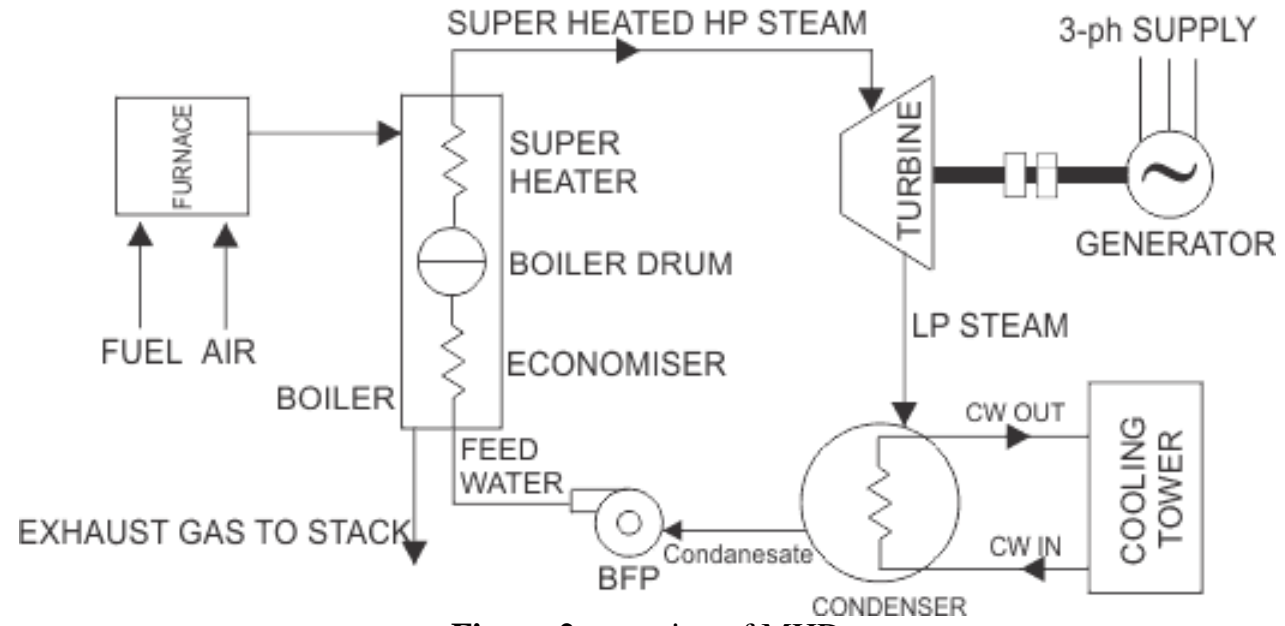

Figure 2 operation of MHD

\section{Magneto hydrodynamics (MHD)}

\section{Literature review}

Magneto hydrodynamics or magneto fluid dynamics is the academic discipline which studies the dynamic of electrically conducting fluids. Examples of such fluids include plasmas, liquid metals, and salt water. The word magneto hydrodynamics (MHD) is derived from magneto- meaning magnetic field, and hydromeaning liquid, and - dynamics meaning movement [2]. The field of MHD was initiated by Hannes Alfven, for which he received the Nobel Prize in physics in 1970.

\section{Magneto hydrodynamic Generator}

The MHD Generator [3] or dynamo transforms thermal energy or kinetic energy directly into electricity. MHD generators are different from traditional electric generators in that they can operate at high temperatures without moving parts. MHD was eagerly developed because the exhaust of a plasma MHD generator is a flame, still able to heat the boilers of a steam power plant [1]. So high-temperature MHD was developed as a topping cycle to increase the efficiency [8] of electric generation, especially when burning coal or natural gas. It has also been applied to pump liquid metals and for quiet submarine engines [5].

The basic concept underlying the mechanical and fluid dynamos is the same. The fluid dynamo, however, uses the motion of fluid or plasma to generate the currents which generate the electrical energy. The mechanical dynamo, in contrast, uses the motion of mechanical devices to accomplish this. The functional difference between an MHD Generator [3] and an MHD dynamo is the path the charged particles [8] follow.

\section{What is Plasma?}

Plasma is the fourth state of matter. To put it very simply, plasma is an ionised gas, a gas into which sufficient energy is provided to free electron from atoms or molecules and to allow species, ions and electrons, to coexist.

\section{Development of MHD power generators}

The first recorded MHD investigation was conducted in 1821 by the English chemist Humphry Davy when he showed that an arc could be deflected by a magnetic field. More than a decade later, Michael Faraday sought to demonstrate motional electromagnetic induction in a conductor moving through Earth's geomagnetic field. To this end, he said up in January 1832 a rudimentary open circuit MHD generator, or flow metre, on the waterloo bridge across the river Thames in London. His experiment was unsuccessful owing to the electrodes being electro chemically polarised, an effect not understood at the time. 
Faraday soon turned his attention to other aspects of electromagnetic induction, and MHD power generation [7] received little attention until the 1920s and '30s, when Bela Karlovitz, a Hungarian- born engineer, first proposed a gaseous MHD system. In 1938 he and Hungarian engineer D.Halasz set up an experimental facility at the westing house electric corporation research laboratories and by 1946 had shown that, through seeding the working gas, small amount of electric power could be extracted. The project was abandoned, however, largely because of lack of understanding of the conditions required to make the work in gas an efficient conductor.

\section{Research significance}

In our state, $65 \%$ of power is generated from thermal power plant and $35 \%$ of power generated from other sources. In India the annual power consumption is about 1, 40,000 MW in which the power deficiency is about 11,000 MW.

MHD Power Generation [7] is a new technique with directly converting the thermal energy into electric power. It was observed [6] that the efficiency of a coal fired thermal power plant is about $40 \%$ and the efficiency [6] of MHD power generation [7] system is about 10-20\%. If this MHD generator [3] is coupled with thermal power plant, the efficiency [6] of the power plant will be increased up to $60 \%$.

In this regard an attempt as been made to study the systematic analysis and performance [6] of a magneto hydrodynamic generator equipped with a coal fired thermal power plant, Tuticorin Thermal Power Station located at thoothukudi district. TTPS is one of the major power generation plant developed in Tamilnadu to meet the growing demand for power. The ultimate capacity of the plant is 1050 MW under 3 stages. The fuel gas coming from the chimney of the plant was taken as the conducting fluid for MHD generator [3] and performed the experimental program.

\section{Selection of input and output}

In the present work it is required to know the maximum power, maximum current, maximum voltage of MHD generator [3] integrated with a coal fired thermal power plant. In this regard, the following readings were taken from different departments of TTPS for calculations. The table $1 \& 2$ gives information about flue as temperature at different points and flue gas analysis.

\section{Furnace}
a) Type
Balanced draft with fussion welded wall construction.
b) Width
$: 11.557 \mathrm{~m}$
c) Depth
$: 12.395 \mathrm{~m}$
d) Volume
$: 4162 \mathrm{~m}^{3}$
e) Furnace pressure
$: 180.54 \mathrm{~kg} / \mathrm{cm}^{2}$
f) Flue gas velocity
$: 22-25 \mathrm{~m} / \mathrm{s}$
g) Quantity of flue gas released in the furnace : 10,00,000 to $11,00,000 \mathrm{~m}^{3} / \mathrm{hr}$
h) Quantity of coal used per stage :6500 to 7000 tones/day.
i) Chimney height (stack height) :220m

Table 1. Flue gas temperature at different points/ different positions

\begin{tabular}{|l|l|l|l|}
\hline S.No. & Flue gas temperature at different points/ different positions & BMCR & NCR \\
\hline 1. & Max furnace axial gas temperature & $1336^{\circ} \mathrm{C}$ & $1328^{0} \mathrm{C}$ \\
2. & Furnace outlet temperature & $1229^{0} \mathrm{C}$ & $1237^{0} \mathrm{C}$ \\
3. & Flue gas temperature at entrance of economiser & $526^{\circ} \mathrm{C}$ & $519^{\circ} \mathrm{C}$ \\
4. & Flue gas temperature at exit of economiser & $353^{\circ} \mathrm{C}$ & $349^{\circ} \mathrm{C}$ \\
5. & Flue gas temperature at inlet of ESP & $144^{0} \mathrm{C}$ & $145^{\circ} \mathrm{C}$ \\
6. & Flue gas temperature at outlet of ESP & $144^{0} \mathrm{C}$ & $145^{\circ} \mathrm{C}$ \\
7. & Flue gas temperature at outlet of chimney & $134^{0} \mathrm{C}$ & $134^{\circ} \mathrm{C}$ \\
\hline
\end{tabular}

Table 2. Flue gas Analysis

\begin{tabular}{|l|l|l|}
\hline S.No. & Flue gas emission & Units \\
\hline 1. & $\mathrm{CO}_{2}$ & $15-15.5 \%$ \\
2. & $\mathrm{O}_{2}$ & $4-4.7 \%$ \\
3. & $\mathrm{SO}_{2}$ & $600-700 \mathrm{mg} / \mathrm{Nm}^{3}$ \\
4. & $\mathrm{NO}_{\mathrm{X}}$ & $30-32 \mathrm{mg} / \mathrm{Nm}^{3}$ \\
5. & $\mathrm{SPM}$ & $80-100 \mathrm{mg} / \mathrm{Nm}^{3}$ \\
\hline
\end{tabular}




\section{Experimental investigation}

Open cycle system

In open cycle system [4] the working fluid after generating electrical energy is discharged to the atmosphere through a stack [1].

In a closed cycle system the working fluid [7] is recycled to the sources [5] and thus used again and again and again. The operation of MHD generator [3] directly on the combustion products [7] in an open cycle system [4].In open cycle system working fluid is air [6] represented in figure 3.

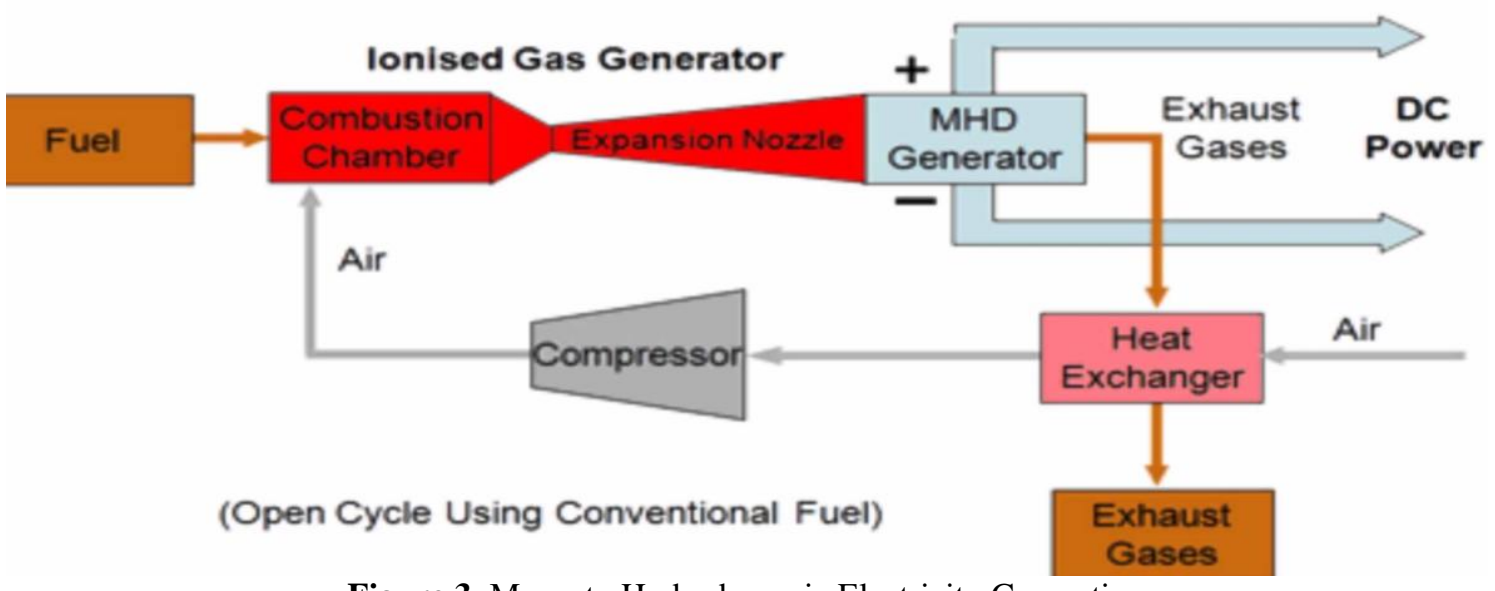

Figure 3. Magneto Hydrodynamic Electricity Generation

Formulae

Maximum power [8]

The open circuit voltage [8]

The max current [8]

Max voltage [8]

Max power [8]

Conversion efficiency [6]

Where

$\sigma=$ The conductivity of the gas [5], mho/m

$\mathrm{B}=$ Magnetic field, $\mathrm{Wb} / \mathrm{m}^{2}$

$\mathrm{u}=$ Velocity of the gas, $\mathrm{m} / \mathrm{s}$

$\mathrm{d}=$ Distance between the electrodes, $\mathrm{m}$

$\mathrm{A}=$ Electrode surface area, $\mathrm{m}^{2}$

\section{Given data (From TTPS)}

$$
\begin{aligned}
& \sigma=15 \mathrm{mho} / \mathrm{m} \\
& \mathrm{u}=775 \mathrm{~m} / \mathrm{s} \\
& \text { Let us assume } \\
& \mathrm{B}=2.5 \mathrm{~Wb} / \mathrm{m}^{2} \\
& \mathrm{~d}=1 \mathrm{~m} \\
& \mathrm{~A}=1.5 \mathrm{~m}^{2} \\
& \text { The open circuit voltage } \mathrm{V}_{\mathrm{o}} \quad=\mathrm{B} \mathrm{u} \text { d volts } \\
& =2.5 \times 775 \times 1 \\
& =1875 \text { volts } \\
& \mathrm{I}_{\max }=\frac{\| B A \sigma}{2} \\
& =\frac{775 \times 2.5 \times 1.5 \times 15}{2} \\
& =21796.875 \mathrm{~A} \\
& \mathrm{~V}_{\max }=\mathrm{u} \mathrm{B} \mathrm{d}-\mathrm{I}_{\max } \frac{d}{\square A} \\
& =1937.5-21796.875 \times \frac{1}{15 \times 1.5}
\end{aligned}
$$




$\begin{aligned} & =1937.5-968.75 \\ & =968.75 \text { volts } \\ & \\ \text { Max power } & \mathrm{V}_{\max } \times \mathrm{I}_{\max } \\ & =968.75 \times 21796.875 \\ & =21.11 \mathrm{MW} \\ \text { Conversion efficiency } \quad \eta \quad=\frac{V_{\max }}{u B} & \\ =\frac{968.75}{775 x 2.5} & \times 100 \\ & =50 \%\end{aligned}$

\footnotetext{
Maximum current $\quad=21796.875 \mathrm{~A}$

Maximum voltage $\quad=968.75$ volts

Maximum power $\quad=21.17 \mathrm{MW}$

Conversion efficiency $=50 \%$
}

\section{Results}

\section{Conclusions}

Based upon the above investigation the following conclusions were drawn. If the proposed MHD Generator is equipped along with the thermal power plant, the efficiency of the plant will be increased by $10 \%$.

Since, we are using flue gases releasing into the atmosphere a conducting fluid to the generator, the effluence in the flue gas were minimized and reduced as the environmental pollution. Effective utilisation of heat energy will takes place for the production of power. Conductivity of the gases can be increased by injecting seeded material (potassium carbonate) in to the flue gases. By equipping MHD generator system in all thermal power plant in India, significant quantity of power can be generated. Besides the use of MHD system for commercial electrical power generation, it has got other uses, to use MHD as the conversion system in a nuclear electrical system of spacecrafts.

\section{Limitations}

Cost of stable superconducting magnet system will be more.

Additional seed recovery techniques are to be adapted, if seeding materials are used.

Life and durability of the materials like (electrodes, insulators) are reduced, as they are exposed to hot exhaust gases and particulate matters.

\section{Acknowledgement}

We are thankful to the Tuticorin Thermal Power Plant officials for providing the required data for completing the project.

\section{References}

[1]. Borghi, C.A. and Ribani, P.L.;"MHD steam Thermal Power Plant Electrical Station with Zero Stack Emission". IEEE Transactions on Energy Conversion, 11, No.1, pp.194-199(1996).

[2]. G.D Rai, "Non - conventional energy resources", 2008, pp.667-670.

[3]. Inui, Y.et al .; "Preliminary study of the performance characteristics of an MHD generator for the compact fusion advanced Rankine cycle", Fusion Engrg. Des. 9, pp.451-455(1989).

[4]. Ishikawa, M. and Umoto, J.; "Environmentally Attractive Oxygen-coal-Fired MHD steam combined system with CO2 Recovery", Energy Conversion and Management, 34, No.8, pp.597-605(1993).

[5]. Kolodziej, P., Bowles, J.V., and Roberts, C.,1998, "Optimizing Hypersonic Sharp Body Concepts from a Thermal Protection System Prespective",8th, AIAA Paper No. 98-1610.

[6]. Louis, J. F. and Holman, R.R.;"A Nuclear Powered Space based Disk MHD Power System Description and Performance Assessment", Proc. 25th Symp. Eng. Aspects MHD, pp.11.1.1-5, Nashville, Tennesse, U.S.A., June (1998).

[7]. Macheret, S. O., Shneider, M.N., and Candler, G.V., 2004, "Modelling of MHD Power Generation on Board Reentry Vehicles", Paper No. AIAA-2004-1024.

[8]. S.K.Dubey, Dr. S. K. Bhargav,"Non - Conventional energy resources”, 2008, pp. 102-105. 